\title{
Silk Fibroin/Spidroin Electrospun Scaffolds for Full-Thickness Skin Wound Healing in Rats
}

\author{
Liubov Safonova $^{1}$, Maria Bobrova ${ }^{1}$, Anton Efimov ${ }^{1}$, Lyubov Davydova ${ }^{2} \mathbb{D}$, Timur Tenchurin ${ }^{2}$, Vladimir Bogush $^{2}$, \\ Olga Agapova ${ }^{1}$ and Igor Agapov ${ }^{1, *}$
}

1 Academician V.I. Shumakov National Medical Research Center of Transplantology and Artificial Organs, Ministry of Health of the Russian Federation, Schukinskaya ul. 1, 123182 Moscow, Russia; saf.lyubov.msu@gmail.com (L.S.); mariabobrova.msu@gmail.com (M.B.); antefimov@gmail.com (A.E.); olya.agape@gmail.com (O.A.)

2 National Research Center "Kurchatov Institute", pl. Academician Kurchatov 1, 123182 Moscow, Russia; davidovlu@gmail.com (L.D.); tenchurin.timur@mail.ru (T.T.); vlbogush@mail.ru (V.B.)

* Correspondence: igor_agapov@mail.ru; Tel.: +7-49523-16042

Citation: Safonova, L.; Bobrova, M.; Efimov, A.; Davydova, L.; Tenchurin, T.; Bogush, V.; Agapova, O.; Agapov, I. Silk Fibroin/Spidroin Electrospun Scaffolds for Full-Thickness Skin Wound Healing in Rats. Pharmaceutics 2021, 13, 1704. https://doi.org/ 10.3390/pharmaceutics13101704

Academic Editor: Alessandro F. Martins

Received: 20 August 2021

Accepted: 12 October 2021

Published: 15 October 2021

Publisher's Note: MDPI stays neutral with regard to jurisdictional claims in published maps and institutional affiliations.

Copyright: (c) 2021 by the authors. Licensee MDPI, Basel, Switzerland. This article is an open access article distributed under the terms and conditions of the Creative Commons Attribution (CC BY) license (https:// creativecommons.org/licenses/by/ $4.0 /)$.

\begin{abstract}
The main goal of our research was to fabricate electrospun scaffolds from three different silk proteins—silk fibroin from Bombyx mori silkworm cocoons and two recombinant spidroins, rS2/12 and rS2/12-RGDS - and to perform a comparative analysis of the structure, biological properties, and regenerative potential of the scaffolds in a full-thickness rat skin wound model. The surface and internal structures were investigated using scanning electron microscopy and scanning probe nanotomography. The structures of the scaffolds were similar. The average fiber diameter of the scaffolds was $315 \pm 26 \mathrm{~nm}$, the volume porosity was $94.5 \pm 1.4 \%$, the surface-to-volume ratio of the scaffolds was $25.4 \pm 4.2 \mu \mathrm{m}^{-1}$ and the fiber surface roughness was $3.8 \pm 0.6 \mathrm{~nm}$. The scaffolds were characterized by a non-cytotoxicity effect and a high level of cytocompatibility with cells. The scaffolds also had high regenerative potential - the healing of the skin wound was accelerated by 19 days compared with the control. A histological analysis did not reveal any fragments of the experimental constructions or areas of inflammation. Thus, novel data on the structure and biological properties of the silk fibroin/spidroin electrospun scaffolds were obtained.
\end{abstract}

Keywords: silk fibroin; recombinant spidroin; electrospinning; scanning probe nanotomography; full-thickness skin wound

\section{Introduction}

One of the main objectives in tissue engineering is the fabrication of cytocompatible constructions and the selection of materials that can perform cell interactions to ensure the physiological activity of the construction. There is a spectrum of requirements for these materials, such as non-toxicity, a defined biodegradation rate, low immunogenicity, etc. The structure of the construction should imitate the native extracellular matrix structure as closely as possible and perform its functions to recreate the native conditions for cells.

This research investigated constructions that were fabricated from three different silk proteins: silk fibroin from cocoons of the Bombyx mori silkworm, and two recombinant spidroins rS2/12 and rS2/12-RGDS.

Silk fibroin is characterized by a unique combination of physico-chemical and biological properties, and can be used in different fields of tissue engineering, both in a solo state and in composites. The main advantage of silk when compared with other cytocompatible materials is its mechanical properties [1], which ensure the fibroin application as a frame-reinforcing component in various constructions [2,3] and as a composite additive to polymers with insufficient mechanical strength [4-6].

The primary structure of fibroin has the main repeating motif GAGAGS, which accounts for $95 \%$ of amino acid residues. The remaining part has an amorphous structure 
and consists mainly of hydrophilic amino acid residues. The secondary structure presents antiparallel $\beta$-layers connected by hydrogen bonds. The amorphous regions form $\alpha$-helices, the proportion of which increases with protein hydration. The tertiary structure includes a heavy chain with a molecular weight of $390 \mathrm{kDa}$ and a light chain of $26 \mathrm{kDa}$ in a 1:1 ratio, connected by disulfide bonds, as well as a P25 glycoprotein of $30 \mathrm{kDa}$, which assemble in a 6:6:1 ratio correspondingly to form a complex [7].

Spidroins are proteins synthesized by spider glands. The formation and structuring processes of the main silk proteins of the orb-weaver spiders Nephila clavipes and Araneus diatematus have been studied extensively. The structural thread consists of two proteins, spidroin 1 and spidroin 2, which form a complex [8]. Both of these proteins are characterized by the presence of a huge number of repetitive sequences in the central part (the socalled primary repeats of $25-40$ amino acid residues in size) and unique sequences of 100-300 amino acid residues at the N- and C-domains. All repeats contain poly-Ala blocks in 4-8 amino acid residues, which alternate with Gly replete regions with the GGX motif for spidroin 1 and the GPGXX motif for spidroin 2. Such an alteration of the hydrophobic and hydrophilic regions of molecules ensures amphiphile properties for interaction with tissues. The presence of up to $15 \%$ of proline residues in the amino acid sequence of spidroin 2, which are absent in spidroin 1 [9], has a significant effect on the further formation of higher-level structures and determines the various properties of these proteins.

Similar to silk fibroin, spidroins are characterized by the ability to phase transition during dehydration. This property makes it possible to ensure the structural stability of the protein in constructions that are based on them.

The attention of researchers on spider proteins is primarily due to the unique mechanical characteristics of these proteins. The tensile strength of spidroins is comparable to the tensile strength of Kevlar, while the elasticity of spidroin is about seven times higher, leading to impressive energy of break values $[10,11]$. Such mechanical characteristics make it possible to consider spidroins as promising materials for use in technology. However, the use of spidroins is still limited by the difficulties associated with obtaining these proteins on an industrial scale.

The development of genetic engineering has made it possible to create recombinant analogues of spidroins that not only have unique mechanical characteristics, but are also cytocompatible, making it possible to consider these spidroins as promising material for the development of tissue-engineered constructions [12,13]. Genetic engineering also makes it possible to create modified forms of recombinant spidroin analogues with a set of properties that correspond to a required task.

On the basis of recombinant spidroins, various materials have been created, such as hydrogels and microgels, porous scaffolds, tubes, scaffolds, films, etc. [14-20].

The electrospinning method is one of the most promising methods for fabricating scaffolds with a defined structure. Electrospun scaffolds have a multilayer fibrous structure with a high porosity and a high surface area-to-volume ratio (SA:V). Many different types of constructions based on silk proteins have been fabricated using the electrospinning method $[17,21]$.

Using a mixture of fibroin and recombinant spidroins makes it possible to create cytocompatible constructions that combine mechanical properties and high cytocompatibility with modification potential. These properties allow the requirements of tissue engineering to be satisfied. Furthermore, fibroin and spidroins are characterized by high strength and an elasticity modulus, which are necessary to accelerate regenerative potential and to reduce surgical trauma.

Thus, in the course of this study, a comparative analysis of the structure, biological properties and regenerative potential of silk fibroin/spidroin electrospun scaffolds was performed and novel data on its structure and biological properties was obtained. 


\section{Materials and Methods}

\subsection{Preparation of Silk Proteins}

Silk fibroin was obtained from B. mori silkworm cocoons [22], which were provided by the head of the State Scientific Institution of the Republican Scientific Research Station of Sericulture of the Russian Academy of Agricultural Sciences (Zheleznovodsk, Stavropol Krai, Russia) Bogoslovsky V.V. To purify the cocoons from sericin, $1 \mathrm{~g}$ of silk was boiled in a water bath for $40 \mathrm{~min}$ in $500 \mathrm{~mL}$ of $2.52 \mathrm{M}$ sodium bicarbonate aqueous solution and washed with $3.6 \mathrm{~L}$ of distilled water. Next, the silk was boiled in $500 \mathrm{~mL}$ of distilled water in a water bath for $30 \mathrm{~min}$ and washed with $3.6 \mathrm{~L}$ of distilled water. The last procedure was repeated three times. The purified silk fibroin was dried at room temperature.

Recombinant spidroins rS2/12 and rS2/12-RGDS were isolated from the waterinsoluble fraction of yeast cell producers and purified by ion-exchange chromatography in an FPLC (Fast protein liquid chromatography) system up to 95\% purity and lyophilized as described earlier [18].

\subsection{Fabrication of Silk Fibroin-Based Microfibrous Scaffolds}

An aqueous solution of silk fibroin was dried in a Petri dish at room temperature. The dried silk fibroin was dissolved in hexafluoro-2-propanol (HFIP) at a rate of $50 \mathrm{mg} / \mathrm{mL}$.

Recombinant spidroins rS2/12 and rS2/12-RGDS were dissolved in HFIP at a rate of $50 \mathrm{mg} / \mathrm{mL}$.

The solutions were centrifuged for $10 \mathrm{~min}$ at $12,100 \times \mathrm{g}$ and then mixed in a volume ratio of 7:3, respectively, to a total protein concentration of $50 \mathrm{mg} / \mathrm{mL}$.

Microfibrous scaffolds were fabricated using the electrospinning method. The solutions were deposited to the fixed collector surface (steel plate) under an electric field with a voltage of $6.8-7 \mathrm{kV}$ through a $23 \mathrm{G}$ needle. The solution feed rate was $0.1 \mathrm{~mL} / \mathrm{h}$, and the needle-collector distance was $7 \mathrm{~cm}$. The scaffolds were dried at room temperature for 2 days, and were then separated. To create scaffolds for cell adhesion and proliferation research, the solutions were deposited with similar parameters on cover glasses that were attached to the collector.

\subsection{Surface Structure Analysis by Scanning Electron Microscopy (SEM)}

The samples of the scaffolds were fixed with a $2.5 \%$ phosphate-buffered glutaraldehyde solution ( $\mathrm{pH}$ 7.4) for $2 \mathrm{~h}$ at $4{ }^{\circ} \mathrm{C}$ in the dark, and were then washed with a phosphatebuffered saline. The samples were dehydrated by transfer through ethanol solutions with increasing concentrations of $10,20,50,70$, and $96 \%$ for $1 \mathrm{~h}$ in each concentration, and incubated in acetone for $30 \mathrm{~min}$.

The samples were then exposed to critical point drying $\left(31^{\circ} \mathrm{C}, 72.8 \mathrm{~kg} / \mathrm{cm}^{2}\right)$ by the Quorum K850 Critical Point Dryer (Quorum Technologies, Lewes, UK). The dried samples were coated with a gold layer with a thickness of $10 \mathrm{~nm}$ in an argon atmosphere at $20 \mathrm{~mA}$ of ion current and 1 mbar of pressure by the Q150R ES rotary-pumped coating system (Quorum Technologies, Lewes, UK). The samples were analyzed using the Tescan Vega3 SBU scanning electron microscope (Tescan, Brno, Czech Republic) with an operating voltage of $15 \mathrm{kV}$. Imaging was performed by VegaTC software (Tescan, Brno, Czech Republic).

\subsection{Analysis of the Construction Structure with Scanning Probe Nanotomography (SPNT)}

The samples were fixed with a $2.5 \%$ phosphate-buffered glutaraldehyde solution (pH 7.4) for $2 \mathrm{~h}$ at $4{ }^{\circ} \mathrm{C}$ in the dark and washed with phosphate-buffered saline. The samples were dehydrated by transfer through ethanol solutions with increasing concentrations of $10,20,50,70$, and $96 \%$ for $1 \mathrm{~h}$ in each concentration. The samples were incubated in propylene oxide for $10 \mathrm{~min}$ twice and transferred into a mixture of epoxy medium and propylene oxide in a ratio of 1:1, then in a mixture of epoxy medium and propylene oxide in a ratio of 2:1. After that, the samples were incubated in an epoxy medium for $30 \mathrm{~min}$ at room temperature. Next, the samples were embedded into the epoxy medium and incubated at $45^{\circ} \mathrm{C}$ for $24 \mathrm{~h}$, and then for another $48 \mathrm{~h}$ at $60{ }^{\circ} \mathrm{C}$. 
The study was performed using the combined Ntegra Tomo system (NT-MDT Co., Zelenograd, Russia), which comprises a scanning probe microscope integrated with the ultramicrotome Leica EM UC6NT (Leica Microsystems GmbH, Vienna, Austria). Serial sections of the sample with a thickness of $150 \mathrm{~nm}$ were performed with the Diatome UltraAFM 45 diamond knife (Diatome, Nidau, Switzerland) on the ultramicrotome, with further measurements of the surface topography of each section taken with an atomic force microscope [23]. The measurements were performed in semi-contact mode with a scanning frequency of $1 \mathrm{~Hz}$. Silicon cantilevers NSG10 with a resonant frequency of $240 \mathrm{kHz}$ (NTMDT, Zelenograd, Russia) were used for the measurements, with a tip curvature radius of no more than $10 \mathrm{~nm}$.

Images were obtained, processed, and surface profiles constructed by Nova 1.0.26.1433 software (NT-MDT, Zelenograd, Russia). To assemble three-dimensional reconstructions, images were aligned at the scanning plane. The three-dimensional structures were analyzed using ImagePro AMS 6.0 software (MediaCybernetics Inc., Rockville, MD, USA), which includes the option of three-dimensional reconstruction.

\subsection{Fourier-Transform Infrared Spectroscopy (FTIR) of Scaffolds}

Spectra were recorded on a Nicolet iS5 (Thermo Scientific, Waltham, MA, USA) instrument using an iD5 ATR device (diamond, $4 \mathrm{~cm}^{-1}$ resolution, 32 scans). A deconvolutional analysis of the amide I band was carried out using Origin 2016 software. To reveal the features of the secondary structure of the protein, the Savitsky-Golay method smoothing procedure was used with polynomials of the second degree over 9 points. The detection of analytical signals in the form of peaks was carried out on the basis of an analysis of the characteristic points of the second derivative. The half-width of the peaks was recorded in the range from 10 to $30 \mathrm{~cm}^{-1}$ [24].

\subsection{Cytotoxicity, Cell Adhesion, and Proliferation Tests}

An analysis of cytotoxicity was performed using the MTT test [25]. The 3T3 mice fibroblasts were cultured in a 96-well plate in DMEM with a low concentration of glucose containing $10 \%$ fetal bovine serum, $0.324 \mathrm{mg} / \mathrm{mL}$ glutamine and $10 \mathrm{mg} / \mathrm{mL}$ gentamicin at $37^{\circ} \mathrm{C}, 5 \% \mathrm{CO}_{2}$ for 3 days. Next, the culture medium was changed and the scaffold samples were put into wells. The plates were incubated at $37{ }^{\circ} \mathrm{C}, 5 \% \mathrm{CO}_{2}$. The MTT test was performed on the 3rd, 5th, and 7th days of the incubation. Per well, $60 \mu \mathrm{L}$ of $5 \mathrm{mg} / \mathrm{mL}$ MTT solution was added. The plates were incubated at $37^{\circ} \mathrm{C}, 5 \% \mathrm{CO}_{2}$ for $4 \mathrm{~h}$. The samples were removed and the plates were centrifuged for $5 \mathrm{~min}$ at $885 \times \mathrm{g}$. The formazan precipitate in each well was dissolved in $300 \mu \mathrm{L}$ of dimethyl sulfoxide per well, and the optical density was measured at $540 \mathrm{~nm}$.

To investigate cell adhesion and proliferative activity, a Hep-G2 cell line was used. The cells were cultured in DMEM with a high concentration of glucose containing $10 \%$ fetal bovine serum, $0.324 \mathrm{mg} / \mathrm{mL}$ glutamine and $10 \mathrm{mg} / \mathrm{mL}$ gentamicin at $37^{\circ} \mathrm{C}, 5 \% \mathrm{CO}_{2}$. The scaffolds on the cover glasses were positioned in Petri dishes with a diameter of $3.5 \mathrm{~cm}$, sterilized with $70 \%$ ethanol for $30 \mathrm{~min}$, and then irradiated with ultraviolet light for $30 \mathrm{~min}$. Next, the scaffolds were washed three times with sterile phosphate-buffered saline and incubated in a culture medium for $30 \mathrm{~min}$. The cell suspension in $4 \mathrm{~mL}$ of culture medium was transferred to Petri dishes at a rate of 20,000 cells per Petri dish and incubated at $37^{\circ} \mathrm{C}, 5 \% \mathrm{CO}_{2}$. Cell adhesion and proliferative activity were evaluated with the Carl Zeiss Axio Vert.A1 microscope (Zeiss, Jena, Germany). The samples were washed twice with phosphate-buffered saline and stained with DAPI fluorescent dye. An amount of $3 \mu \mathrm{g} / \mathrm{mL}$ of aqueous DAPI solution was added at a rate of $2 \mathrm{~mL}$ per Petri dish and incubated at $37^{\circ} \mathrm{C}$, $5 \% \mathrm{CO}_{2}$ for $5 \mathrm{~min}$. Subsequently, the samples were washed twice with phosphate-buffered saline. Cell images were obtained and processed with ZEN 2.3 (blue edition) software (Zeiss, Jena, Germany). 


\subsection{Full-Thickness Skin Wound Healing of Wistar Rats}

Male Wistar rats weighing 200-300 g were used for the experiment. The rats were isolated from each other in single cages with free access to water and food. All animal experiments were performed in accordance with European Convention for the Protection of Vertebrate Animals Used for Experimental and other Scientific Purposes (ETS) and Directive 2010/63/EU, and approved by the Local Ethical Committee of the V.I. Shumakov Federal Research Center of Transplantology and Artificial Organs.

All operations on the animals were performed under inhalation ether anesthesia, which was provided with a desiccator at a rate of $50 \mathrm{mg} / \mathrm{kg}$ body weight. The animals were in spontaneous respiration with a frequency of $75 \pm 10$ respiratory cycles per minute, corresponding to the surgical stage of anesthesia.

The animals were divided into three groups (Table 1). In group 1 (control group), the same surgical procedures were performed on all the animals, and the wounds were covered with sterile gauze dressings.

Table 1. Experimental groups with 5 animals in each group.

\begin{tabular}{cc}
\hline Group Number & Wound Dressing Description \\
\hline 1 & - (control) \\
2 & MS (silk fibroin + rS2 $/ 12)$ \\
3 & MS-RGD (silk fibroin + rS2/12-RGDS) \\
\hline
\end{tabular}

The modeling of a full-thickness skin wound was performed as follows [26]. Hairs from the back of a rat were removed, and the skin was treated with a $0.05 \%$ chlorhexidine solution. Next, a wound with a diameter of $15 \pm 1 \mathrm{~mm}$ was made and treated with a $0.05 \%$ chlorhexidine solution. The depth of the damage corresponded to the thickness of the rat skin, including epidermis, dermis and hypodermis.

Scaffolds were sterilized for $1 \mathrm{~h}$ with an ultraviolet light and placed on the wound area in a dry form. Next, the dressing wound was treated with a $0.05 \%$ chlorhexidine solution and coated with sterile gauze dressing, which was removed on the third day of the experiment.

The diameter of the wound (d) was measured and the wound healing area (A) was calculated on 0th, 3rd, 7th, 14th, 21st, 23rd, 28th, and 40th days of the experiment according to the formula:

$$
A=\frac{d_{(0)}-d_{(0,3,7,14,21,23,28,40)}}{d_{(0)}} \times 100 \%
$$

A-wound healing area,

$\mathrm{d}_{(0)}$-initial wound diameter (day 0 ),

$\mathrm{d}_{(0,3,7,14,21,23,28,40)}$ - wound diameter on the control day of the experiment.

Subsequently, the curves of the dynamics of the wound closure process were plotted.

\subsection{Histological Evaluation}

The samples of rat skin that were $20 \pm 3 \mathrm{~mm}$ in size were fixed by a mixture of formalin, ethanol and acetic acid in a 4:1:0.3 volume ratio and were embedded into paraffin. The paraffin blocks were sliced; sections with a thickness of $10 \mu \mathrm{m}$ were obtained using a Microm HM 325 rotary microtome (Thermo Scientific, Waltham, MA, USA), stained with hematoxylin-eosin, embedded in Canada balsam and analyzed using a Carl Zeiss Axio Vert.A1 microscope (Zeiss, Jena, Germany). Images were obtained with a Axiocam 305 color digital camera (Zeiss, Jena, Germany) and processed using ZEN 2.3 (blue edition) software (Zeiss, Jena, Germany). 


\subsection{Statistical Processing of Results}

Data were processed using analysis of variance (ANOVA). The statistical significance of the results was evaluated by the Mann-Whitney U test. The level of statistical significance $\alpha$ was equal to 0.05 .

\section{Results and Discussion}

In the course of the study, two groups of scaffolds based on a mixture of fibroin and two variants of recombinant spidroin were fabricated using an electrospinning process (Figure 1A). Spidroin rS2/12 was included in the scaffolds of the first group, and spidroin rS2/12, containing at the C-terminus the amino acid sequence RGDS attached via a linker of 10 amino acid residues (GGSGG SGGSGG), was included in the scaffolds of the second group $[12,13]$. The RGDS amino acid sequence was introduced into the molecule in order to improve the adhesive properties of the constructions that were based on it, and to increase their cytocompatibility. The amphiphilic properties of these proteins contributed to the same goals, as did their positive charge over the entire range of physiological $\mathrm{pH}$ values (pI 10.13 for both types of spidroins). The inclusion of spidroins in the composition of scaffolds makes it possible to increase their cytocompatibility without reducing their mechanical characteristics (in particular, mechanical strength and elasticity), which is an advantage for scaffold implantation as it facilitates surgical procedures.
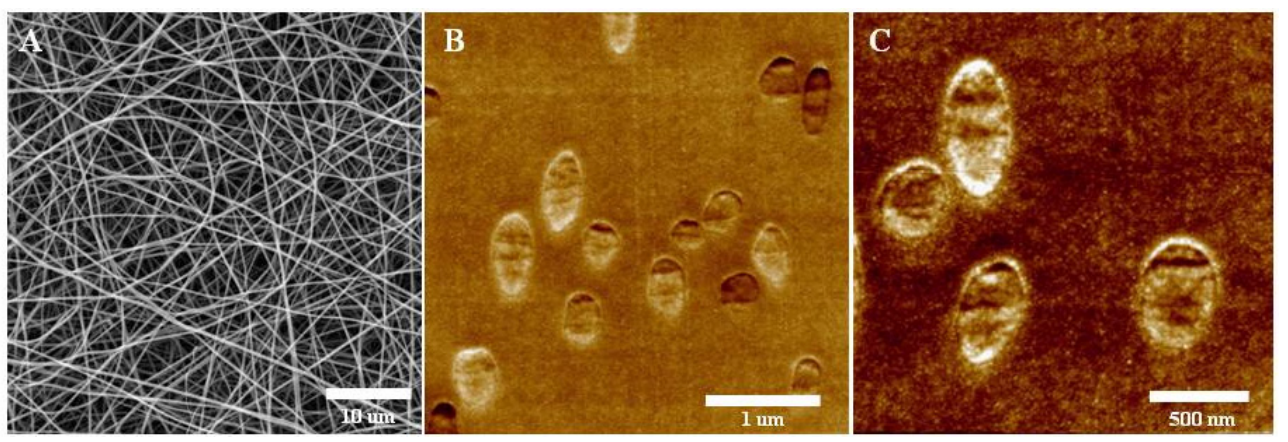

Figure 1. Structure of MS-RGD scaffolds: (A)—SEM image, $(\mathbf{B}, \mathbf{C})-S P M$ image. Images of MS scaffolds are not presented due to the absence of significant structural differences.

To fabricate the scaffolds, the electrospinning method was used as it allows for obtaining constructions with a high surface area-to-volume ratio, as well as those with a high porosity index. These structure properties ensure its closeness to the native extracellular matrix structure, providing its high cytocompatibility.

The structure of the fabricated scaffolds was analyzed using two methods. The SEM method (Figure 1A) made it possible to confirm the porous fibrous structure of the scaffolds, as well as to estimate the average thickness of the fibers in their composition, which was $328 \pm 57 \mathrm{~nm}$. The fibers in the scaffolds did not have a specific orientation and were stacked in several layers. To analyze the structure of the scaffolds with a high resolution and to estimate the quantitative parameters of the structure, the SPNT method was used (Figure 1B,C). Scanning probe microscopy (SPM) images were obtained to reflect the distribution of fibers in the volume of the scaffold (Figure 1B), and SPM images of the structure of the individual fibers were also obtained (Figure 1C). Here, we performed SPM measurements of the epoxy embedded scaffold blockfaces after section by the ultramicrotome with use of Scanning Probe Nanotomography (SPNT) technique and analyzed distribution of the cross-sections of the electrospun fibers. The images were used to calculate the crucial quantitative parameters of the structure of the fabricated scaffolds. The average fiber diameter in the scaffolds was $315 \pm 26 \mathrm{~nm}$, the volume porosity of the scaffolds was $94.5 \pm 1.4 \%$, the ratio of the fiber surface to the scaffold volume was $25.4 \pm 4.2 \mu \mathrm{m}^{-1}$ and the fiber surface roughness was $3.8 \pm 0.6 \mathrm{~nm}$. The calculated parameters were comparable for both groups of scaffolds. 
Within the framework of this study, the quantitative parameters of the structure of the fabricated MS and MS-RGD scaffolds were for the first time estimated using the unique technology of SPNT. This technology allows the high-resolution visualization of the structure of sample surface after ultrathin sections and the calculation of their threedimensional structure parameters. This method makes it possible to precisely determine the value of the scaffold fiber thickness and to confirm the uneven distribution of the fibers in the scaffold volume, as well as to calculate the crucial parameters of the structure [27-29]. Scaffolds have a high porosity index (over 90\%) and a high surface area-to-volume ratio, which ensures the efficient migration of cells in the volume of scaffolds and provides a microenvironment for their adhesion. Fibers in scaffolds have a nanorelief on the surface, which also affects cell adhesion.

The FTIR spectra analysis results of the scaffolds (Figure 2, Table 2) are characterized by the presence of bands that are typical for nitrogen compounds [30-33]: $3276 \mathrm{~cm}^{-1}$ (stretching vibrations of N-H bonds), $1639 \mathrm{~cm}^{-1}$ (with a shoulder in the region of $1650 \mathrm{~cm}^{-1}$, amide I band, stretching vibration $\mathrm{C}=\mathrm{O}$ ), $1526 \mathrm{~cm}^{-1}$ and its overtone at $3072 \mathrm{~cm}^{-1}$ (amide II band $\mathrm{N}-\mathrm{H}$ bending vibrations and C-N stretching vibrations) and $1205-1280 \mathrm{~cm}^{-1}$ (amide III band $\mathrm{N}-\mathrm{H}$ bending vibrations $+\mathrm{C}=\mathrm{O}$ bending vibrations $+\mathrm{C}-\mathrm{C}$ stretching vibrations). The results show that the introduction of spidroins into the composition of the fibroin-based scaffold does not significantly increase the content of $\beta$-sheets.
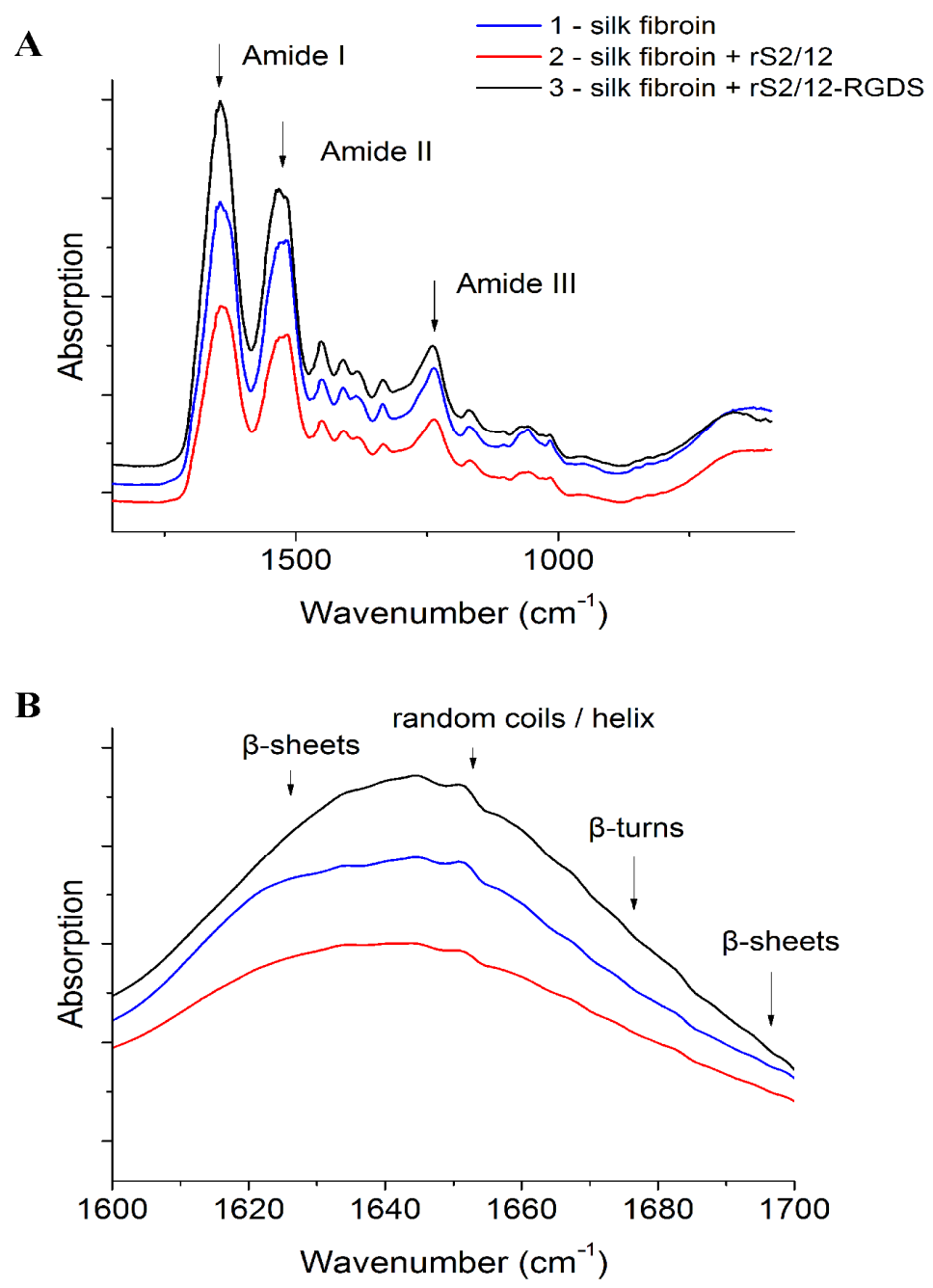

Figure 2. FTIR spectra of silk fibroin and spidroin-based scaffolds (A). The region of amide I (B) is shown separately. 
Table 2. Deconvolution of the second derivative and the spectrum of scaffolds in the region of amide I depending on the composition of proteins.

\begin{tabular}{cccc}
\hline \multirow{2}{*}{ Conformation } & \multicolumn{3}{c}{ Content of Conformation, \% } \\
\cline { 2 - 4 } & Fibroin Electrospun Scaffold & MS & MS-RGD \\
\hline$\beta$-turn & 22 & 27 & 22 \\
$\beta$-sheet & 42 & 46 & 33 \\
Amorphous region & 19 & 10 & 26 \\
$\alpha$-helix & 17 & 27 & 19 \\
\hline
\end{tabular}

According to the cytotoxicity assay results, the fabricated scaffolds did not have a toxic effect on the cells, and the proliferative activity of the cells increased in experimental samples (Figure 3A).
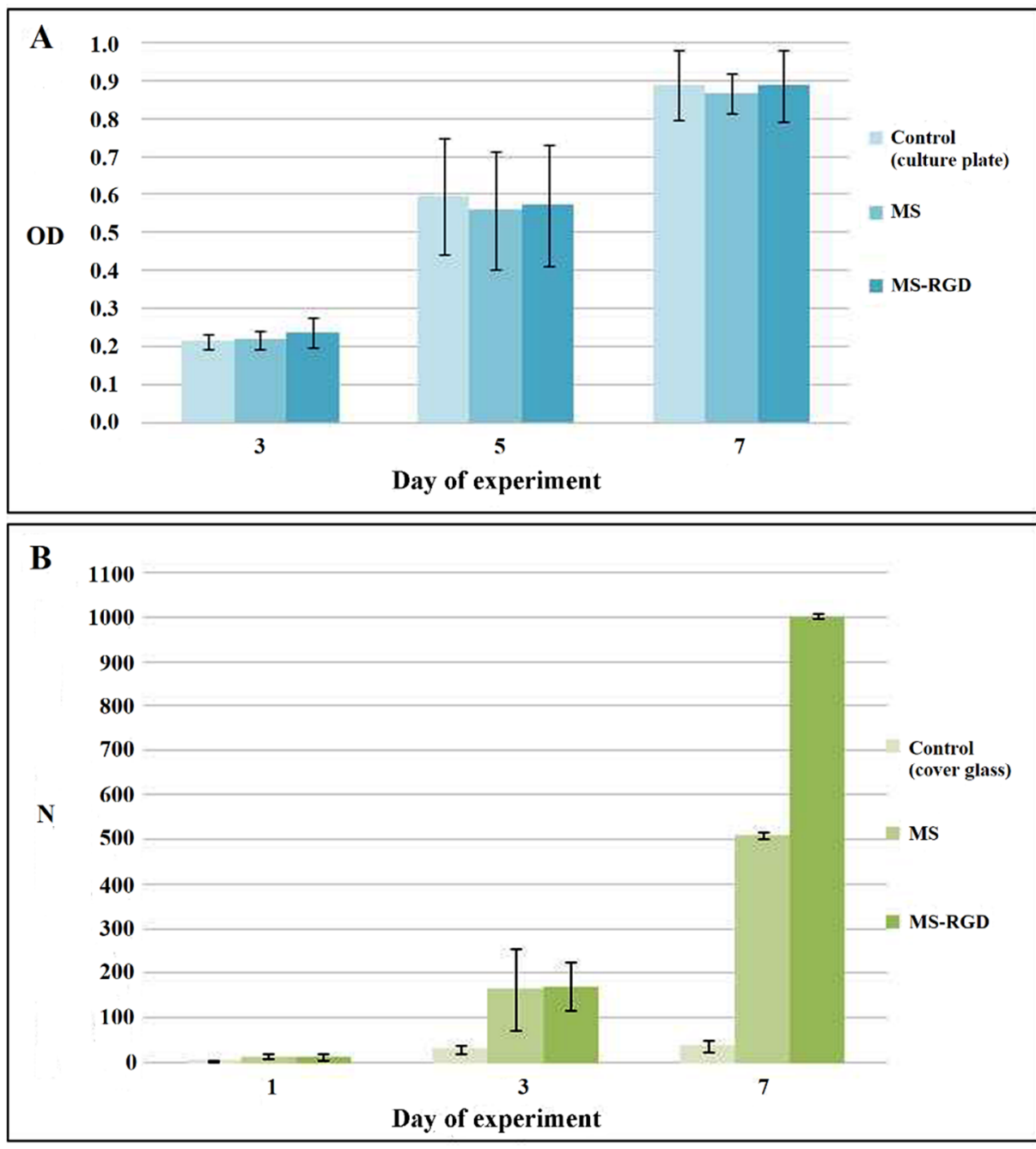

Figure 3. Results of experiments on the study of the cytotoxicity of the fabricated scaffolds and analysis of adhesion and proliferation of cells. (A): cytotoxicity on days 3, 5, and 7 of the experiment on the model of proliferation of mice 3T3 fibroblasts (MTT test-optical density at $540 \mathrm{~nm}$ of formazan solution in DMSO). The values of the standard deviation for 3 independent measurements are shown. (B): adhesion (1 day) and proliferative activity ( 3,7 days) of Hep-G2 cells (cell quantity in microscopic field of $850 \times 709 \mu \mathrm{m})$. Standard deviation values for 5 independent measurements are shown.

An analysis of the cell adhesion and proliferation on the scaffolds was performed by counting the cell nuclei stained with DAPI fluorescent dye (Figure 3B). During the 
experiment, the scaffolds maintained cell adhesion at a level comparable to the control samples. No effect of the presence of the RGDS sequence on cell adhesion was found. This may be due to the fact that RGDS could be locked from cell receptors by fibroin molecules which do not contain such sequences. On the third day of the experiment, there was a significant increase in the proliferative activity of cells in the experimental constructions compared with the control samples. This can be explained both by the natural cytocompatible properties of fibroin and spidroins, due to their ability to provide a high level of cell proliferative activity, and by the porous structure of the constructions. On the seventh day of the experiment, the proliferative activity of cells in the scaffolds continued to increase; however, on constructions containing the RGDS sequence, it was significantly higher, which may be associated with the gradual degradation of fibers and the unlocking of the RGDS sequences, improving cell adhesion. Cell adhesion to the samples was uneven; cell migration into the deeper layers of the scaffolds was observed. In addition, there were areas of active cell proliferation into the samples without a cell monolayer.

The fabricated scaffolds were successfully used as wound dressings for the fullthickness rat skin wound healing models (Figure 4). The constructions were used as wound dressings, which were positioned on the wound surface in a dry state. This positioning option does not lead to the formation of structural defects in scaffolds. The high-swelling property of the constructions ensures convenient implantation without causing additional damage, due to the absence of suture material fixated on the wound. According to the results of the experiments, the scaffolds accelerated the healing of the skin by 19 days compared with the control group, which is an indicator of the high regenerative potential of scaffolds (Table 3, Figure 5). At the first stages of wound healing, a similar effect was detected in the scaffolds containing the RGDS sequence as in vitro experiments, i.e., cells actively proliferated, leading to accelerated healing compared with other groups of animals.

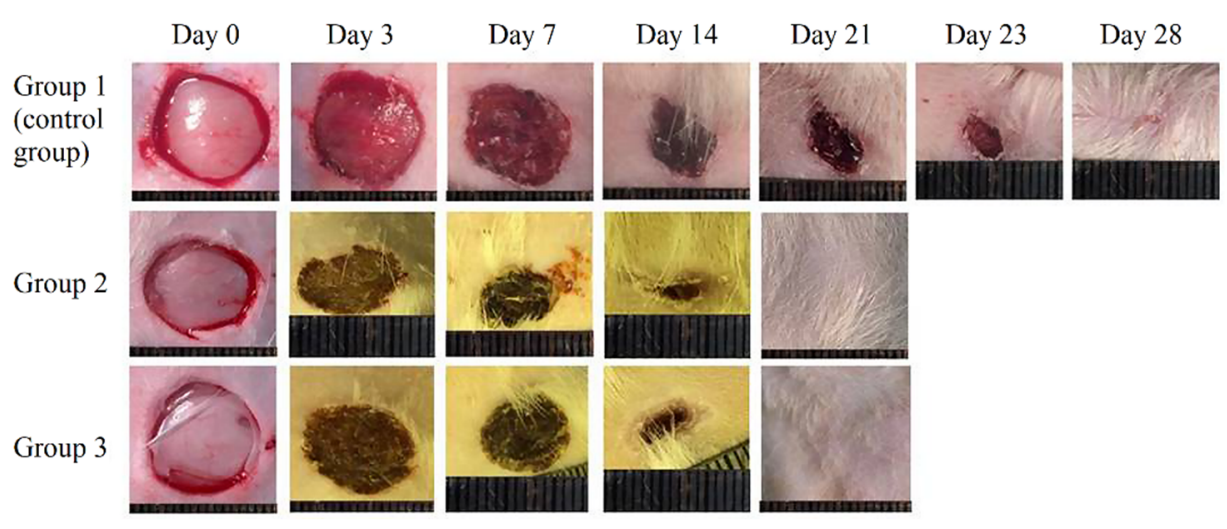

Figure 4. Images of wounds on days $0,3,7,14,21,23$, and 28 of the experiment. Complete healing of the wound in the control group occurred on the 40th day of the experiment (image not shown).

Table 3. Dynamics of full-thickness skin wound healing in Wistar rats (standard deviation values for 5 independent measurements are shown). Sign " $" *$ "indicates statistically significant differences between the experimental groups and the control group.

\begin{tabular}{cccccccc}
\hline \multirow{2}{*}{ Group Number } & \multicolumn{7}{c}{ Wound Healing Area (\%) } \\
\cline { 2 - 7 } & 0 Day & 3 Day & 7 Day & 14 Day & 21 Day & 23 Day & 28 Day \\
\hline 1 (control group) & 0 & 0 & $12.5 \pm 1.0$ & $50.0 \pm 1.5$ & $68.0 \pm 1.5$ & $75.0 \pm 1.5$ & $87.5 \pm 1.7$ \\
2 (MS) & 0 & 0 & $7.0 \pm 1.2$ & $61.0 \pm 1.2^{*}$ & $100^{*}$ & & \\
3 (MS-RGDS) & 0 & 0 & $23.0 \pm 1.5^{*}$ & $64.0 \pm 0.6^{*}$ & $100^{*}$ & & \\
\hline
\end{tabular}




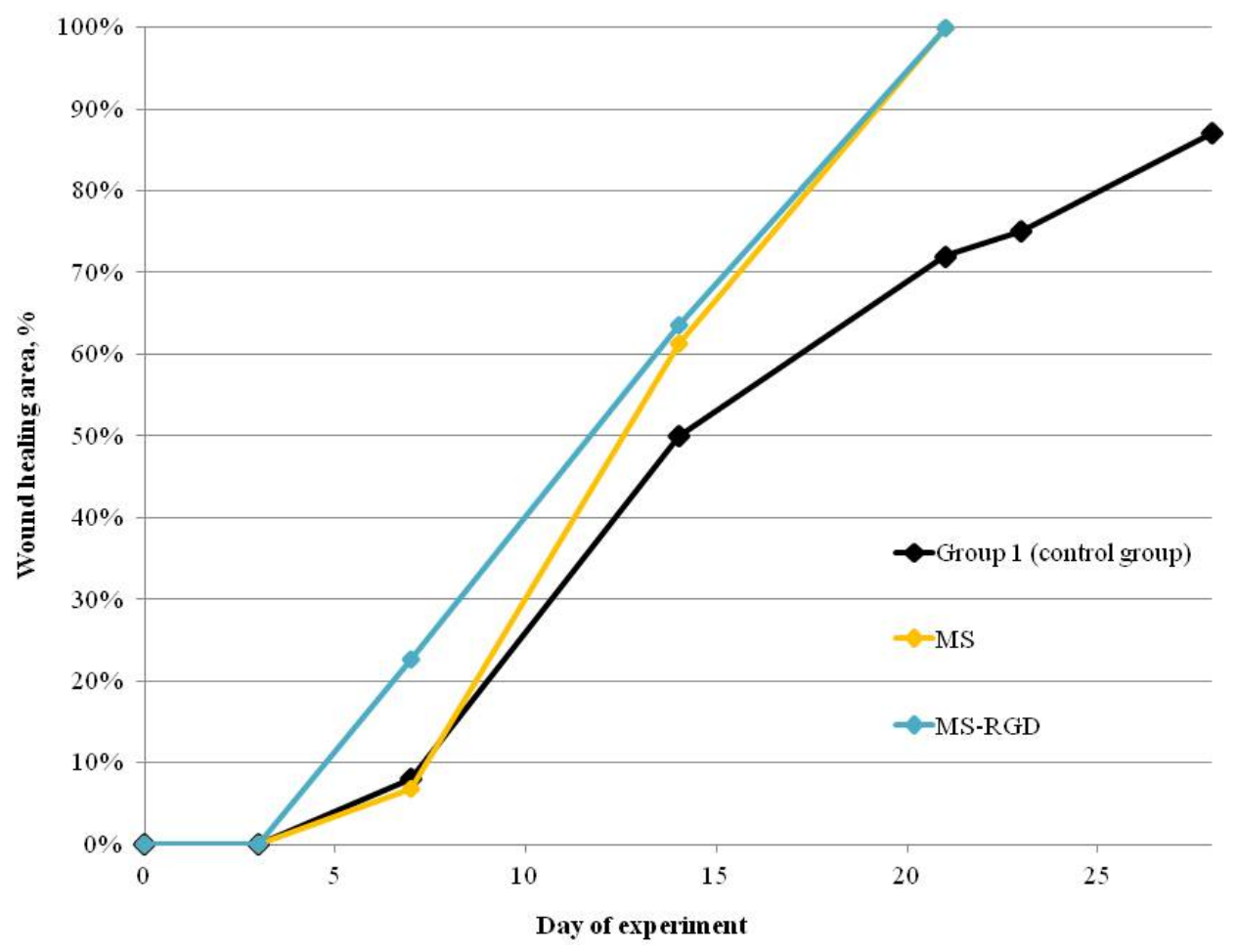

Figure 5. Wistar rat skin healing curves.

A histological evaluation of skin samples in the area of complete wound healing $(\mathrm{A}=100 \%)$ revealed the restoration of three layers of skin in all the experimental animalsepidermis, dermis, and hypodermis—-which indicates successful wound healing (Figure 6). In this case, the morphology of sections of skin samples from the experimental animals does not differ from the morphology of sections of the native intact skin of a rat. No fragments of experimental scaffolds were found on the obtained sections, which indicates their complete biodegradation during skin healing. Furthermore, no foci of inflammation were identified, which is an important indicator characterizing the successful healing of skin. The results are in agreement with the data on the scarless healing of full-thickness skin wounds in rats obtained by a subcutaneous injection of microgels based on recombinant spidroin rS1/9 under the wound edges [34]. 


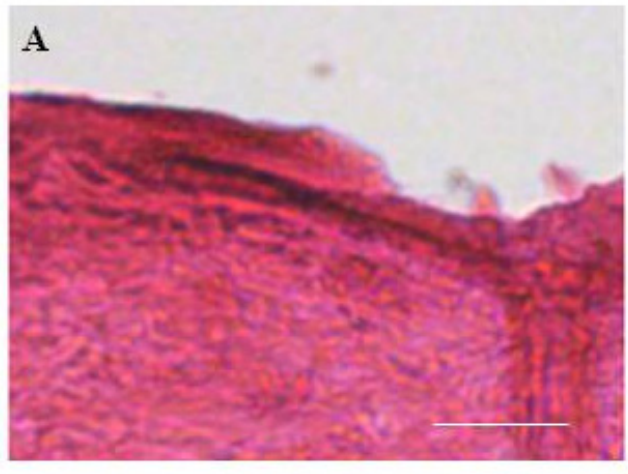

$\mathbf{B}$

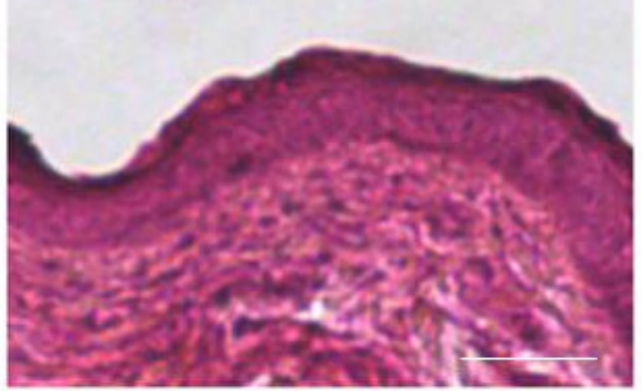

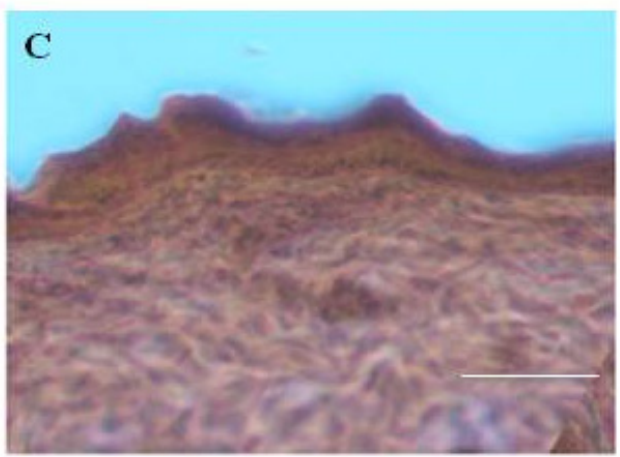

D

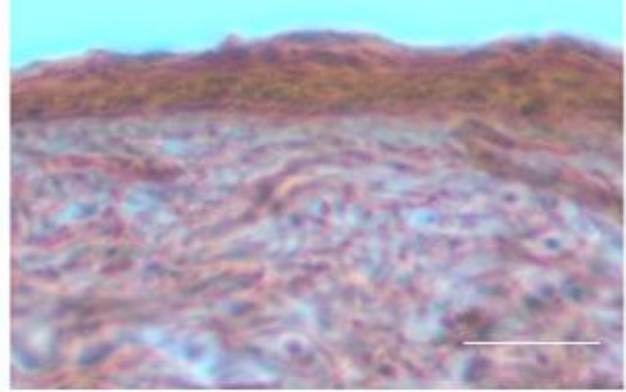

Figure 6. Images of histological sections of rat skin in the area of complete wound healing $(A=100 \%)$, stained with hematoxylin-eosin, magnification $\times 100$, scale: $100 \mu \mathrm{m}$. (A): native rat skin (normal); (B): group 1 on the 40th day of the experiment; (C): group 2 on the 23rd day of the experiment; (D): group 3 on the 23 rd day of the experiment.

\section{Conclusions}

Within the framework of this study, two types of construction were fabricated based on silk fibroin containing recombinant spidroins rS2/12 and rS2/12-RGDS as composite additives correspondingly. These compositions were used for fabrication of the electrospun microfibrous scaffolds for the first time. The quantitative parameters of the structure of the electrospun scaffolds were estimated using the SEM method and the unique technology of SPNT. The novel data on micro- and nanostructure of electrospun scaffolds were obtained by SPNT technology. The fabricated constructions had no toxic effect on cells and were cytocompatible in vitro and biocompatible in vivo. The high regenerative potential of the constructions was shown: the rates of wound healing in both experimental groups were comparable with each other, and significantly (about two times) higher than one in the control group. Thus, the fabricated electrospun scaffolds can be considered as promising structures for promotion of wound healing.

Author Contributions: L.S., M.B. and A.E., writing and editing; L.S., M.B., A.E., L.D. and T.T., methodology and investigation; A.E. and O.A., visualization; V.B. and I.A., conceptualization, project administration and supervision. All authors have read and agreed to the published version of the manuscript.

Funding: This study was partially supported by an internal grant from the National Research Center "Kurchatov Institute" (Order No. 1779 dated 9 November 2020) in part of the recombinant spidroin biosynthesis, and partially supported by a grant from the President of the Russian Federation for Supporting Leading Scientific Schools of the Russian Federation, project no. NSh-2598.2020.7 in part of the structural characterization of the scaffolds and in vivo experiments.

Institutional Review Board Statement: The study was conducted according to the guidelines of the Declaration of Helsinki, and approved by the Local Ethical Committee of V.I. Shumakov Federal Research Center of Transplantology and Artificial Organs (protocol \#24/1, 7 August 2015). 
Informed Consent Statement: Not applicable.

Data Availability Statement: The data presented in this study are available on request from the corresponding author.

Acknowledgments: FTIR spectroscopy measurements were carried out using equipment from the "Optics" resource center of the National Research Center "Kurchatov Institute". The authors are grateful to Sergey N. Malakhov for the FTIR studies.

Conflicts of Interest: The authors declare no conflict of interest.

\section{References}

1. Stoppato, M.; Stevens, H.Y.; Carletti, E.; Migliaresi, C.; Motta, A.; Guldberg, R.E. Effects of silk fibroin fiber incorporation on mechanical properties, endothelial cell colonization and vascularization of PDLLA scaffolds. Biomaterials 2013, 34, $4573-4581$. [CrossRef]

2. Mobini, S.; Hoyer, B.; Solati-Hashjin, M.; Lode, A.; Nosoudi, N.; Samadikuchaksaraei, A.; Gelinsky, M. Fabrication and characterization of regenerated silk scaffolds reinforced with natural silk fibers. J. Biomed. Mater. Res. A 2013, 101, $2392-2404$. [CrossRef] [PubMed]

3. Park, S.; Edwards, S.; Hou, S.; Boudreau, R.; Yee, R.; Jeong, K.J. Multi-interpenetrating network (ipn) hydrogel by gelatin and silk fibroin. Biomater. Sci. 2019, 7, 1276-1280. [CrossRef] [PubMed]

4. Panas-Perez, E.; Gatt, C.J.; Dunn, M.G. Development of a silk and collagen fiber scaffold for anterior cruciate ligament reconstruction. J. Mater. Sci. Mater. Med. 2013, 24, 257-265. [CrossRef]

5. Ghezzi, C.E.; Marelli, B.; Muja, N.; Hirota, N.; Martin, J.G.; Barralet, J.E.; Alessandrino, A.; Freddi, G.; Nazhat, S.N. Mesenchymal stem cell-seeded multilayered dense collagen-silk fibroin hybrid for tissue engineering applications. Biotechnol. J. 2011, 6, 1198-1207. [CrossRef]

6. Vasconcelos, A.; Gomes, A.C.; Cavaco-Paulo, A. Novel silk fibroin/elastin wound dressing. Acta Biomater. 2012, 8, 3049-3060. [CrossRef] [PubMed]

7. He, Y.-H.; Zhang, N.N.; Li, W.-F.; Jia, N.; Chen, B.-Y.; Zhou, K.; Zhang, J.; Chen, Y.; Zhou, C.Z. N-Terminal domain of Bombyx Mori fibroin mediates the assembly of silk in response to $\mathrm{pH}$ decrease. J. Mol. Biol. 2012, 418, 197-207. [CrossRef]

8. Gatesy, J.; Hayashi, C.; Motrin, R.D.; Woods, J.; Lewis, R. Extreme diversity, conservation and convergence of spider silk fibroin sequences. Science 2001, 291, 2603-2605. [CrossRef]

9. Hayashi, C.Y.; Shipley, N.H.; Lewis, R.V. Hypotheses that correlate the sequence, structure, and mechanical properties of spider silk proteins. Int. J. Biol. Macromol. 1999, 24, 271-275. [CrossRef]

10. Hinman, M.B.; Jones, J.A.; Lewis, R.V. Synthetic spider silk: A modular fiber. Trends Biotechnol. 2000, 18, 374-379. [CrossRef]

11. Blackledge, T.A. Spider silk: A brief review and prospectus on research linking biomechanics and ecology in draglines and orb webs. J. Arachnol. 2012, 40,1-12. [CrossRef]

12. Bogush, V.G.; Sidoruk, K.V.; Davydova, L.I.; Zalunin, I.A.; Kozlov, D.G.; Moisenovich, M.M.; Agapov, I.I.; Kirpichnikov, M.P.; Debabov, V.G. Recombinant analogue of spidroin 2 for biomedical materials. Dokl. Biochem. Biophys. 2011, 441, 276-279. [CrossRef]

13. Bogush, V.G.; Sokolova, O.S.; Davydova, L.I.; Klinov, D.V.; Sidoruk, K.V.; Esipova, N.G.; Neretina, T.V.; Orchanskyi, I.A.; Makeev, V.Y.; Tumanyan, V.G.; et al. A novel model system for design of biomaterials based on recombinant analogs of spider silk proteins. J. Neuroimmune Pharm. 2009, 4, 17-27. [CrossRef]

14. Salehi, S.; Koeck, K.; Scheibel, T. Spider Silk for Tissue Engineering Applications. Molecules 2020, 25, 737. [CrossRef]

15. Debabov, V.G.; Bogush, V.G. Recombinant Spidroins as the Basis for New Materials. ACS Biomater. Sci. Eng. 2020, 6, 3745-3761. [CrossRef] [PubMed]

16. Teplenin, A.; Krasheninnikova, A.; Agladze, N.; Sidoruk, K.; Agapova, O.; Agapov, I.; Bogush, V.; Agladze, K. Functional analysis of the engineered cardiac tissue grown on recombinant spidroin fiber meshes. PLoS ONE 2015, 10, e0121155. [CrossRef] [PubMed]

17. Zhao, L.; Chen, D.; Yao, Q.; Li, M. Studies on the use of recombinant spider silk protein/polyvinyl alcohol electrospinning membrane as wound dressing. Int. J. Nanomed. 2017, 12, 8103-8114. [CrossRef] [PubMed]

18. Baklaushev, V.P.; Bogush, V.G.; Kalsin, V.A.; Sovetnikov, N.N.; Samoilova, E.M.; Revkova, V.A.; Sidoruk, K.V.; Konoplyannikov, M.A.; Timashev, P.S.; Kotova, S.L.; et al. Tissue Engineered Neural Constructs Composed of Neural Precursor Cells, Recombinant Spidroin and PRP for Neural Tissue Regeneration. Sci. Rep. 2019, 9, 3161. [CrossRef] [PubMed]

19. Moisenovich, M.M.; Malyuchenko, N.V.; Arkhipova, A.Y.; Kotlyarova, M.S.; Davydova, L.I.; Goncharenko, A.V.; Agapova, O.I.; Drutskaya, M.S.; Bogush, V.G.; Agapov, I.I.; et al. Novel 3D-microcarriers from recombinant spidroin for regenerative medicine. Dokl. Biochem. Biophys. 2015, 463, 232-235. [CrossRef] [PubMed]

20. Moisenovich, M.M.; Pustovalova, O.; Shackelford, J.; Vasiljeva, T.V.; Druzhinina, T.V.; Kamenchuk, Y.A.; Guzeev, V.V.; Sokolova, O.S.; Bogush, V.G.; Debabov, V.G.; et al. Tissue regeneration in vivo within recombinant spidroin 1 scaffolds. Biomaterials 2012, 33, 3887-3898. [CrossRef] [PubMed]

21. Meng, Z.X.; Wang, Y.S.; Ma, C.; Zheng, W.; Li, L.; Zheng, Y.F. Electrospinning of PLGA/gelatin randomly oriented and aligned nanofibers as potential scaffold in tissue engineering. Mater. Sci. Eng. 2010, 30, 1204-1210. [CrossRef] 
22. Safonova, L.A.; Bobrova, M.M.; Agapova, O.I.; Kotliarova, M.S.; Arkhipova, A.Y.; Moisenovich, M.M.; Agapov, I.I. Biological properties of regenerated silk fibroin films. Sovrem. Tehnol. V Med. 2015, 7, 6-13. [CrossRef]

23. Efimov, A.E.; Agapov, I.I.; Agapova, O.I.; Oleinikov, V.A.; Mezin, A.V.; Molinari, M.; Nabiev, I.; Mochalov, K.E. A novel design of a scanning probe microscope integrated with an ultramicrotome for serial block-face nanotomography. Rev. Sci. Instrum. 2017, 88, 032701. [CrossRef]

24. Belton, D.J.; Plowright, R.; Kaplan, D.L.; Perry, C.C. A robust spectroscopic method for the determination of protein conformational composition-Application to the annealing of silk. Acta. Biomater. 2018, 73, 355-364. [CrossRef] [PubMed]

25. Mosmann, T. Rapid colorimetric assay for cellular growth and survival: Application to proliferation and cytotoxicity assays. $J$. Immunol. Met. 1983, 65, 55-63. [CrossRef]

26. Safonova, L.A.; Bobrova, M.M.; Agapova, O.I.; Arkhipova, A.Y.; Goncharenko, A.V.; Agapov, I.I. Fibroin silk based films for rat's full-thickness skin wound regeneration. Russ. J. Transpl. Artif. Organs 2016, 18, 74-84. [CrossRef]

27. Efimov, A.E.; Agapova, O.I.; Safonova, L.A.; Bobrova, M.M.; Parfenov, V.A.; Koudan, E.V.; Pereira, F.D.A.S.; Bulanova, E.A.; Mironov, V.A.; Agapov, I.I. 3D scanning probe nanotomography of tissue spheroid fibroblasts interacting with electrospun polyurethane scaffold. Express Polym. Lett. 2019, 13, 632-641. [CrossRef]

28. Efimov, A.E.; Moisenovich, M.M.; Bogush, V.G.; Agapov, I.I. 3D nanostructural analysis of silk fibroin and recombinant spidroin 1 scaffolds by scanning probe nanotomography. RSC Adv. 2014, 4, 60943-60947. [CrossRef]

29. Safonova, L.; Bobrova, M.; Efimov, A.; Lyundup, A.; Agapova, O.; Agapov, I. A Comparative Analysis of the Structure and Biological Properties of Films and Microfibrous Scaffolds Based on Silk Fibroin. Pharmaceutics 2021, 13, 1561. [CrossRef]

30. Silverstein, R.M.; Webster, F.X.; Kiemle, D. Spectrophotometric Identification of Organic Compounds, 7th ed.; John Wiley \& Sons, Inc.: Hoboken, NJ, USA, 2005.

31. Conti, E.; Barbagallo, E.; Battiato, S.; Marletta, A.; Costa, G.; Samperi, F. Do habitat features affect the composition of silk proteins by Namibian arid-adapted Ariadna spiders (Araneae: Segestriidae)? Ital. J. Zool. 2015, 82, 48-60. [CrossRef]

32. Malakhov, S.N.; Belousov, S.I.; Shcherbina, M.A.; Meshchankina, M.Y.; Chvalun, S.N.; Shepelev, A.D. Effect of low molecular additives on the electrospinning of nonwoven materials from a polyamide-6 melt. Polym. Sci. A 2016, 58, 236-245. [CrossRef]

33. Tenchurin, T.K.; Istranov, L.P.; Istranova, E.V.; Shepelev, A.D.; Mamagulashvili, V.G.; Malakhov, S.N.; Kamyshinskii, R.A.; Orekhv, A.S.; Vasil'ev, A.L.; Sytin, E.V.; et al. Nano- and Microfibrous Materials Based on Collagen for Tissue Engineering: Synthesis, Structure, and Properties. Nanotechnol. Russ. 2018, 13, 476-486. [CrossRef]

34. Nosenko, M.A.; Moysenovich, A.M.; Zvartsev, R.V.; Arkhipova, A.Y.; Zhdanova, A.S.; Agapov, I.I.; Vasilieva, T.V.; Bogush, V.G.; Debabov, V.G.; Nedospasov, S.A.; et al. Novel Biodegradable Polymeric Microparticles Facilitate Scarless Wound Healing by Promoting Re-epithelialization and Inhibiting Fibrosis. Front. Immunol. 2018, 9, 2851. [CrossRef] 